\title{
Expatriates of Malaysian Construction Company's Psychological Comfort in Foreign Lands
}

\author{
Halmi Zainoli1, Abdul Malek A Tambi², Nor Eeda Ali ${ }^{3}$, Hazirah Azami ${ }^{4}$
}

\author{
1,h3,4 Faculty of Architecture Planning and Surveying, \\ Universiti Teknologi MARA, Perak Branch, Malaysia \\ 2 Faculty of Business and Management, \\ Universiti Sultan Zainal Abidin, Terengganu, Malaysia \\ halmizainol@gmail.com, malekahmad@unisza.edu.my, noree038@uitm.edu.my, hazirahazami1@gmail.com \\ Tel: +6019-5582282
}

\begin{abstract}
Malaysian expatriates prefer to work in foreign countries because of better facilities, working environments and the benefits. However, during the assignment abroad, other unexpected issues arose due to the unforeseen circumstances. It leads to psychological comfort faced by expatriates because of the inability to adjust to the new culture and environment. The aimed of the study is to identify the components that led to psychological comfort. Four components have been disclosed that dominated to expatriates satisfaction. The components that influences were interaction, living environment, reward and social life. These components contribute to the success of expatriates in a foreign country.
\end{abstract}

Keywords: Psychological comfort; Expatriate; Construction

eISSN: 2398-4287C 2020. The Authors. Published for AMER ABRA cE-Bsby e-International Publishing House, Ltd., UK. This is an open-access article under the CC BYNC-ND license (http://creativecommons.org/licenses/by-ncnd/4.0/). Peer-review under responsibility of AMER (Association of Malaysian Environment-Behaviour Researchers), ABRA (Association of Behavioural Researchers on Asians) and CE-Bs (Centre for Environment-Behaviour Studies), Faculty of Architecture, Planning \& Surveying, Universiti Teknologi MARA, Malaysia.

DOI: https://doi.org/10.21834/jabs.v5i17.373 


\subsection{Introduction}

The number of international multinational construction firms in Malaysia has been growing year after year. The rapid economic growth and globalisation of Malaysia enabled Malaysian companies to operate aborad (Zainol \& Aziz, 2010). Spectacular socio-economic development has taken place all around, and thriving construction industries are apparent everywhere in the country. Construction is a high employment source in any country. One may find the primary role of an expatriate manager as a catalyst that ensures the longevity of an organisation's retention of expatriates.

Data on Malaysian expatriates working outside the country are rising year after year. It was estimated in 2019, about 150,000 Malaysians employed in the United States, Australia, Canada and the United Kingdom were highly skilled and experienced. Expatriates in Malaysia with more significant conscientiousness personality fared better in their task and contextual performance. Nevertheless, Malaysian expatriates who are working abroad, and are peculiarly Malaysian, face the burden of cross-cultural adjustment. As a result, the feeling of unsatisfactory adjustment leads to poor performance emerging from "cross-border assignments." The critical factor that contributes to Malaysian expatriates struggling in their assignments was their difficulty in adjusting to a new atmosphere (Zainol, Isa, Alauddin \& Derus 2016).

The study aimed to identify the elements that contributed to the psychological comfort of Malaysian expatriates on assignment with Malaysian companies abroad. Researchers had examined various concepts to provide meaning to the psychological comfort. According to Pinto et al., ( 2017), psychological comfort is associated with health and quality of life of the individual. Besides that, Halim, Bakar, and Mohamad (2019) stated that comfort was related to everything contributing to the well-being and convenience of the life aspects and living conditions improved in the existing place. Thus, the psychological comfort of expatriates concerning various issues related to the foreign cultural environment, such as climate, food, health care, shopping and housing condition (Froese \& Peltokorpi, 2011). Different interpersonal styles used in the foreign culture reflected the degree of psychological comfort in foreign lands (Peltokorpi \& Ramaswami, 2019). Cultural differences are inevitable between international and local values in which the expatriates encounter challenges.

\subsection{State of the art of literature review}

Psychological comfort relates to individual feeling and more complex needs, which are produced by the environment and lifestyle to which the individual has to adapt. Expatriate's psychological comfort concerned various aspects of the foreign culture environment, such as climate, food, healthcare, shopping, and housing condition (Froese \& Peltokorpi, 2011). According to Stroppa and Spieß, (2011), psychological comfort was characterised by a feeling of satisfaction with a different aspect of life and a sense of relative comfort in both countries of origin and the foreign society.

People who sense this negative emotional state would not be able to work efficiently and effectively. On the other hand, people would sense they occupy a quality work environment if 
it is inclusive and supportive to foreign workers. An expatriate is generally defined as a person with professionals with skills or knowledge and lives or works outside his or her home country. Foreign lands refer to another country where a company runs its business. The company's central headquarters at the home country regularly interacted with foreign country nationals to coordinate and monitor projects (Fitzpatrick \& Fitzpatrick, 2017). Psychological comfort related to expatriates who lived and worked outside the home country started to learn about the foreign culture, and make efforts to find successful ways of functioning in a foreign country (Moran, Harris \& Moran, 2011). They voluntarily pursued employment opportunities abroad and tended to maintain a degree of flexibility and freedom in their interactions, living environment, reward, and social life.

The research focuses on the expatriates' psychological comfort, which influenced interaction adjustment, living environment, reward, and social life. Expatriates working abroad will not be facing the same cultural atmosphere and working environment such as in Malaysia. Hence, it is essential to examine psychological comfort elements that affect expatriates because they have to adapt to the new environment abroad.

\subsection{Interaction}

The interaction was related to the comfort levels when engaging or interacting with foreign nationals at work and in nonwork situations (Okpara, 2016). Language ability of expatriates in a foreign country was positively associated with socio-cultural adjustment (Selmer, \& Lauring, 2011). Interaction adjustment focuses on socialising and speaking with nationals of the foreign country by way of interacting with foreign nationals and participating in their social life to improve effectiveness and commitment. The expatriate who has exposure to daily interactions with other expatriates or foreign nationals will require less cross-cultural adjustment, compared to those who do not interact with each other. The interaction also involves conforming to cultural norms. Psychological comfort reflects personal living and social interaction of an individual.

Adjustment of social interaction involves with the fulfilment of basic needs for services, including entertainment, healthcare, shopping and banking as well as the living cost associated with the location other than the home country (Zainol et al., 2016). It was also related to an individual's care for their health that requires an awareness of the physical condition, stress reduction and self-responsibility (Pinto et al., 2017). Those behaviours would help expatriates to experience psychological comfort at the I host country. The research had derived the influencing elements of expatriate psychological comfort, namely, interaction, living environment, reward, and social interaction. By adopting the model, expatriates could achieve psychological comfort and feel highly motivated while performing their assignment in the host country. According to Ying, Ibrahim and Zubir (2020), public spaces for social interaction are essential in organisation. The outcome is twofold; one is rising ineffectiveness and organisational performance, and the other is improving the quality of life. 


\subsection{Living environment}

The living environment is also a significant element because expatriates are trying to adjust to the living standard in the host country lest they faced difficulties (Black, 1998). Some expatriates who live in a host country tend to compare the living environment with their home country where it is more comfortable. One of the reasons expatriates refused an offer to work in the host country was the gap in the standard of living even if it is higher than the home country. Psychological comfort was related to living and housing condition (Zainol et al., 2016; Fitzpatrick \& Fitzpatrick, 2019) and health care facilities (Vianen, Pater, Kristof-Brown, \& Johnson, 2004). Lin, Robbins, and Lin (2019) claimed that the principal elements of psychological comfort were religious practices and good engagement with local people. Unsatisfactory living conditions or difficulty in getting the kinds of food they favour may lead individuals to experience psychological discomfort (Caligiuri, Hyland, Joshi \& Bross, 1998; Halim et al., 2019). Expatriates are exposed to the elements in the living environment on a daily basis during their stay in the host country.

Social interactions and living environment with nationals of host countries are closely linked to one another. When adapting to a new culture and situation in the host country, the expatriate needs to build a new social network with its people. Those who can accept the differences in the host country become aware of the appropriate behaviours to display (Zainordin, Tan, \& Mei, 2015). Deeper interaction can help bridge the gap between home and host cultures. It may provide additional sources of information and assist in the understanding of the host country's culture.

\subsection{Reward}

Rewards and benefits also affect psychological comfort because one would be able to acquire life's necessities and support as well as enjoy everyday life. Expatriates would feel that their organisation values them after completing the tasks assigned to them en route to achieving organisational goals. The reward is also a part of the basic needs of expatriates, and it seems to influence expatriate's decision to remain in or leave the organisation. Besides, expatriates who are looking for more experience and working in the long term should be satisfied with intrinsic rewards such as promotion, recognition, authority, career development, and other intangible benefits.

Psychological comfort is also related to the types and amount of reward. Expatriation can be a rewarding experience in various ways. Their reward or remuneration package included salary, benefits, and other compensations, covering financial and non-financial incentives (Horwitz, 2017). According to Wahab (2014), compensation practices and types of reward affected expatriates' decision whether to remain in or leave their organisation. The reward package may be focused on the strength of the link between pay and performance. Financial rewards are often associated with job opportunities that influence employees' retention.

An attractive salary is an incentive for expatriates to accept an international assignment. Job satisfaction will be compromised if the expatriate receives low wages that could spur their migration to other companies. According to Horwitz (2017), one of the reasons expatriates accept international assignments was the low salary they received in their home country. A 
study by Rasool, Jundong, and Sohail (2017) had found that rewards and benefits had a positive relationship with job satisfaction. Promotion, salary, benefits, and the chance to learn new knowledge and skills were the typical expectations of employees in developed economies.

\subsection{Social Life}

Social life is among the components that influence psychological comfort. Expatriates' social life attributes in a foreign country are food, shopping, banking, cost of living, entertainment, and health care (Zainol et al., 2016). Banking is required to support spending activities like shopping. There were differences in the way people do shopping for food in the home country as compared with the foreign country. Lin et al. (2019) observed that expatriates needed to adjust to shopping activities because some foreign countries practised bargaining while the home country may not.

The study has found, expatriates would discover new things, notably different types of food when they were in their foreign country. Expatriates needed to prepare for the changes that they will be facing, including prior exposure to unfamiliar kinds of food to help with their adjustment in the foreign country. The view was supported by Fisher ( 2015), who acknowledged that change to food was more crucial compared with adjustment to health care, cost of living, and entertainment. However, social life adjustment was also related to engaging socially in any given circumstances, apart from the fulfilment of individuals' daily life needs (Fitzpatrick, 2019). Having a social life network was a fundamental factor in adjusting with culture in a foreign country that was new to the expatriate.

As mentioned by Lin et al. (2019) and Fitzpatrick (2019), some foreign expatriates required adjustment of social life, particularly in areas of interaction, living environment, reward and daily comfort. Therefore, when expatriates move to another country, they will start to learn about foreign culture and make efforts to find successful ways of functioning there. The research focused on expatriate psychological comfort and explanation on why expatriates have difficulties in adapting to the foreign country environment.

\subsection{Research Methodology}

The research had involved a review of pertinent literature on past research findings to identify the elements influencing the psychological comfort and psychological comfort of individuals. Relevant journal articles, proceedings, and books were sought. The literature review was conducted in three phases. In the first stage, the researchers explored the phenomenon of interest, i.e., an expatriate adjustment in the foreign country. The information gathered included related theories on expatriate adjustment and their components, variables, and definition of terms. In the second stage, the information gathered in phase 1 was examined to generate the elements that influence of expatriates' psychological comfort/comfort. In the third phase, the key elements that influence psychological comfort were recapitulated and modelled.

\subsection{Discussion and Findings}


Limited research regarding Malaysian's expatriate, especially in the construction industry working abroad was found. The study also shows four elements influenced the psychological comfort of expatriates. The psychological comfort of Malaysian professional expatriates components is interaction adjustment, living environment, reward and social life. Among interaction adjustment elements are language ability, communication in foreign country and knowledge. Interaction adjustment with foreign nationals refers to the degree of psychological comfort regarding different disclosure and interpersonal styles used in a foreign culture. Living environment elements are living condition such as living condition, housing condition and religious practice. The reward components, including benefits and compensation. Another component influence psychological comfort is social life which includes shopping, banking, cost of living, entertainment \& recreation. Those elements of psychological comfort could influence on expatriates.

Interaction component includes socialising, communication, speaking, and culture is seen as essential to adjustment. Cultural distance or cultural dissimilarity has been another critical factor in predicting adjustment as does linguistic ability, general knowledge about foreign culture and quality of interaction with the foreign country. Even though some of these elements may belong to different categories, there are possibilities that the variables can interact with each other to enable successful adjustment. For example, language ability is very much needed for expatriates (or spouse and children) to communicate with the foreign. Excellent communication skills will ensure that the expatriate can communicate, interact and perform their job satisfactorily, thus enhance his/her adjustment (refer to Fig. 1). In this regard, Vlaj, Caputo, Marzi, \& Dabi (2019) suggested that the organisation should provide language training and social opportunities for expatriates to interact with foreign nationals.

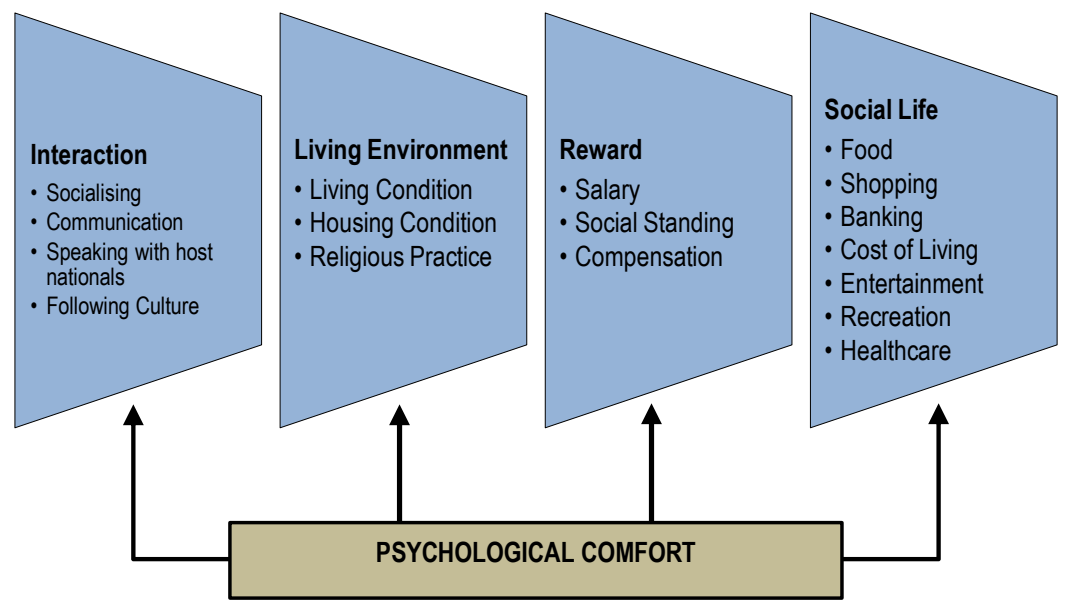

Figure 1: Psychology Comfort Components 
The definition of expatriate adjustment also stresses the relationships between expatriates and local employees. This addresses three elements, such as general, interactional and work-related. While interactional ones 'involves comfortably socialising and interacting with foreign nationals. Presbitero \& Quita (2017) found that, among other factors, frequent interactions of expatriates with locals as well as their self-efficacy had a positive impact on their adjustment. In contrast, Froese and Peltokorpi (2011) displayed that such interaction affects an expatriate's job satisfaction negatively if the cultural distance between he/she and locals is substantive. Stroppa \& Spieß (2011), suggested that the stress experienced by sojourners is caused by the inability to adjust to the foreign culture socially. Which primarily results from their lack of social skills needed in dealing with the new situation that an individual might face when dealing with an unfamiliar culture.

Living environment analysis showed the variables were grouped into three components, namely living conditions, housing and religious practice. In a foreign country, the living environment may cause stress. Expatriates also report living spaces in their home environment and those in the new environment, again causing stress (Barna, 1983). Findings by (Fish \& Fish, 2006; Naithani \& Jha, 2014) showed that adjustment to the living environment is positively correlated with adjustment of expatriates in their foreign countries. This indicates that adaptation to living environment influences the adjustment of expatriates in their foreign countries.

The factors determining the expatriate 's reward are income, social status and insurance (Tung, 1998). The most important in compensation was the expatriate wage. It is because of high salaries and benefits during expatriation that expatriates are considered one of the most valuable resources in an organisation. Expatriates salaries are usually considered a salary is higher than that of the local employees due to the following reasons: (i) salary of a candidate selected for an international assignment has to motivate expatriate would agree to go abroad for work and usually high; (ii) expatriates find it more challenging to live in a foreign country; therefore, living compensation is required which is typically sufficient to pay all taxes without causing a decrease in expatriate real income; (iii) a higher salary is sometimes related to a higher position or rank, which is a stimulus to go to a foreign country; (iv) salary promotion is also considered as compensation for the inconveniences experienced while abroad especially for different environments, climates, homes and so on.

Research by Rasool et al. (2017) found that rewards and benefits have a positive relationship with job satisfaction. In developed economies, for example, promotion, compensation, benefits packages, and the ability to learn new knowledge, skills, and all sorts of benefits are well established among employees. Rewards and benefits also influence psychological comfort in such a way that daily life can be appreciated; every life supported and bought the necessities. Reward also a part of the basic needs of expatriates, and it seems to influence expatriate's decision to stay or leave the organisation. Besides, for those expatriates are looking more experience and working in the long term should be satisfied with intrinsic rewards such as promotions, recognitions, authority, career development and other intangible benefits Rasool et al., (2017). The primary source of support and provide benefits and services of national host company give before arriving and once in the foreign country 
that will affect the expatriate's quality of life and work abroad. Thus, expatriates feel that welfare is taken care of in a foreign country. Both aspects, such as salary and social status, also described reasonable satisfaction in term of reward. It indicates that consideration given by the company to the Malaysian executive is less. Such a situation has also resulted in dissatisfaction among Malaysian expatriate executives. Social networks play an essential role in expatriate adjustment and job performance. Scholars have stressed, the idea of social network and clarify that this help expatriates obtain social support from host and home country nationals. This support helps them to adjust to the foreign country and improve their job performance.

Elements of social life include food, shopping, banking, living costs, entertainment/recreation, and health care services (Zainol \& Aziz, 2010). Social life is essential with general adjustment; thus, expatriates facing different types of adjustments such as food, shopping, etc. (Zhuang, Wu, \& Wen, 2013). Past expatriate studies indicate that these basic individual needs influence general expatriate adjustment. The expatriates need to make a social life change in a foreign country. Accessing all the elements in a foreign country is different while in the home country. Social life is essential in daily needs. If expatriates can accept the differences, the expatriates tend to stay longer in the organisation. Otherwise, expatriates did not satisfied or unable to enjoy the social life in abroad could early return to the home country. Cost of living in a foreign country is exciting, but, it can also be a challenge if not capable of sustaining living comfortably. Expatriates in abroad who are followed similar daily life in the home country, especially custom and living environment will not be having difficulties to adjustment with the home country. Thus, expatriates can reduce the intention to leave and increase the retention in the organisation. However, the challenges in adapting to the new environment will lead the expatriate to leave the organisation or early return to the home country.

The study indicated the most psychological comfort among expatriates that is interaction, living condition, reward and social life. This has to take into account the psychological comfort, in conjunction to reduce the propensity to leave, which eventually may lead to brain drain. As mentioned by Jauhar \& Yusoff (2011), seeing that the brain drain of our Malaysian professionals will continue to affect Malaysia's transformation. As a developing country, Malaysia is searching for more professional and more experienced employees. Along with Malaysia's strategies for developing human capital which can help the country achieve its vision to become a developed nation and smart communities by 2050 .

\subsection{Conclusion}

This investigation adds to the comprehension of the psychological comfort of a Malaysian expert in a foreign country. Four components are influencing the psychological comfort are namely interaction adjustment, living environment, reward and social life. The selection of an expatriate for the international assignment does involve not only technical expertise but also the ability of an individual to adjust and accept a new normal in the foreign country. Hence, international companies must get support from the workers and foreign country nationals, 
especially the professionals who are assigned to work overseas. Malaysia is one developing country which is not spared from this phenomenon that is detrimental to the economy.

Psychological comfort is about the needs, which are more complex and produced by environments and lifestyle to which the individual has to adapt. The psychological comfort needs would influence the overall expatriates' lives. From that, it could be seen whether expatriates can adjust to the new environment or not. Psychological comfort also will affect the working environment. They still need psychological comfort adjustment while working. Hence, expatriates could retain or leave in the organisation. It is challenging to retain Malaysians who are skilled and professional if there are better remuneration and reward offered by other companies overseas. Although it will lead to the loss of Malaysia's talents and affect the economy, they will be bringing back priceless experience when they return home.

Nevertheless, Malaysia could be faced with a shortage of professionals within the country due to the highest demand for Malaysian professionals working internationally. Malaysia is facing a talent crisis because of a lack of skilled and knowledgeable professionals. The study needs to focus more on the strength, skill and talent of the professionals. This will create a better workplace environment and also well-being. The improvement of psychological comfort has an impact on individual, society, economy and country, thus enables the country to be a developed nation. All entities must work together to improve living conditions and a better quality of life. The study is also helping to propose successful preventive action for Malaysian professionals for a better and sustainable workplace.

\section{Acknowledgement}

The authors would like to thank Universiti Teknologi MARA and Ministry of High Education (MOHE), Malaysia, for funding this research (FRGS/1/2018/SSI08/UiTM/02/1. The authors are also thankful to all organisations and individuals who supported to this research.

\section{References}

Black, J.S. (1988), Work Role Transitions: A Study of American Expatriate Managers in Japan. Journal of International Business Studies, 19(2), 277 - 294.

Barna, L. M. (1983). The stress factor in intercultural relations. In D. Landis \& R. W. Brislin (Eds.), Handbook of intercultural training (Vol. 2): 19-49.

Caligiuri, P. M., Hyland, M. M., Joshi, A., \& Bross, A. S. (1998). Testing a theoretical model for examining the relationship between family adjustment and expatriates' work adjustment. Journal of Applied Psychology, 83(4), 598614.

Davies, S., Kraeh, A. \& Froese, F. (2014) Burden or support? The influence of partner nationality on expatriate crosscultural adjustment. Journal of Global Mobility. 3(2), 169-182.

Fish, A., \& Fish, A. (2006). Assisting cross-border manager adjustment interventions. Personel Review. 34(2). 
https://doi.org/10.1108/00483480510579448. 225-245.

Fisher, K. (2015). Pioneers across war zones : The lived acculturation experiences of US female military expatriates. International Journal of Intercultural Relations.. https://doi.org/10.1016/j.ijntrel.2015.05.005. 265-277.

Fitzpatrick, F. (2019). Coping with authoritarianism in international relocation. Critical Perspectives on International Business. 1742-4043.

Fitzpatrick, F., \& Fitzpatrick, F. (2017). Taking the "culture " out of "culture shock" - a critical review of literature on cross-cultural adjustment in international relocation. Critical Perspectives on International Business. https://doi.org/10.1108/cpoib-01-2017-0008. 1742-2043

Fitzpatrick, F., \& Fitzpatrick, F. (2019). Coping with authoritarianism in international relocation A case of cross-cultural adjustment research in context - Cuba. Critical Perspectives on International Review. https://doi.org/10.1108/cpoib01-2018-0003. 1742-2043

Froese, F. J., \& Peltokorpi, V. (2011). Cultural distance and expatriate job satisfaction. International Journal of Intercultural Relations, 35(1), 49-60. https://doi.org/10.1016/j.ijintrel.2010.10.002

Halim, H., Bakar, H. A., \& Mohamad, B. (2019). Expatriation in Malaysia : Predictors of Cross-Cultural Adjustment among Hotel Expatriates. International Journal of Supply Chain Management. 8(1), 664-675.

Horwitz, F. (2017). International HRM in South African multinational companies. Journal of International Management, 23(2), https://doi.org/10.1016/j.intman.2017.01.005. 208-222.

Jauhar, J. \& Yusoff, Y. M. (2011). Brain Drain: Propensity to Leave by Malaysian Professionals. International Journal of Innovation, Management and Technology, 2(2). 119-122.

Leung, M., Chan, I. Y. S. \& Cooper, C. L. (2019) Stress Management in the Construction Industry. Retrieved 29 January 2019 from https://onlinelibrary.wiley.com/doi/book/10.1002/9781118456361.

Lin, P., Robbins, N., \& Lin, P. (2019). Research of Media Industry's Expatriates ' Cross-Culture Adjustment on the Job Involvement and Work Stress : The Impact of Relatedness. Realities in a Kaleidoscope. 64. 120-129

Moran R.T., Harris P.R., \& Moran S.V. (2011), Managing Cultural Differences: Global Leadership Strategies for the 21st Century. Oxford. UK.

Naithani, P., \& Jha, A. N. (2014). Challenges Faced by Expatriate Workers in Gulf Cooperation Council Countries. International Journal of Business and Management, 5(1), https://doi.org/10.5539/ijbm.v5n1p98. 98-104.

Okpara, J. O. (2016) Cross-cultural adjustment of expatriate: Exploring factors influencing adjustment of expatriates in Nigeria. International Journal of Cross Cultural Management, 1-22.

Pinto, S., Fumincelli, L., Mazzo, A., Caldeira, S., \& Martins, J. C. (2017). Comfort, well-being and quality of life: Discussion of the differences and similarities among the concepts. Porto Biomedical Journal, 2(1), 6-12.

Peltokorpi, V., \& Ramaswami, A. (2019). Abusive supervision and subordinates ' physical and mental health : the effects of job satisfaction and power distance orientation. The International Journal of Human Resource Management, https://doi.org/10.1080/09585192.2018.1511617. 1-27.

Presbitero, A., \& Quita, C. (2017). Expatriate career intentions : Links to career adaptability and cultural intelligence. $98,118-126$. 
Rasool, A., Jundong, H., \& Sohail, M. T., (2017). Relationship of Intrinsic and Extrinsic Rewards on Job Motivation and Job Satisfaction of Expatriates in China. Journal of Applied Sciences, 17: 116-125.

Selmer, J., \& Lauring, J. (2011). Host country language ability and expatriate adjustment: the moderating effect of language difficulty. The International Journal of Human Resource Management, 26(3), 401-420.

Stroppa, C., \& Spieß, E. (2011). International assignments: The role of social support and personal initiative. International Journal of Intercultural Relations, 35(2), https://doi.org/10.1016/j.jijntrel.2010.09.008. 234-245.

Tung, R. L. (1998). A contingency framework of selection and training of expatriates revisited. Human Resource Management Review, 8(1), 23-37.

Vlaj, D., Caputo, A., Marzi, G., \& Dabi, M. (2019). Expatriates managers ' cultural intelligence as promoter of knowledge transfer in multinational companies. 94, https://doi.org/10.1016/j.jbusres.2018.01.033. 367-377.

Vianen, V., Pater, I.D., E., Kristof-Brown, A. L., \& Johnson, E. C. (2004) Fitting in: Surface- and Deep-Level Cultural Differences and Expatriates' Adjustment. Academy of Management Journal, 47(5), 697-709.

Wahab, M. A. (2014). The Occurrence of Brain Drain in Malaysia : Perceptions on to Work or not to Work Overseas in the Future. 5(5), 480-489.

Yang, C.K., Inrahim, F.I., \& Zubir, Z (2020). Analysing Spaces for Social Interaction in Coworking Space: A Case Study on Common Ground Damansara Heights. Environment-Behaviour Proceedings Journal, 5(13), 379-386.

Zainol, H., Isa, H. M., Alauddin, K., \& Derus, M. M. (2016). General Adjustment Influence Factor of Malaysian Construction Expatriates Executives Abroad. 00012, 10-15.

Zainol, H. \& Aziz, A. R. A. (2010) Personal Adjustment for expatriate Academy of Management Journal, 47(5), 697709.

Zainordin, N., Tan, C., \& Mei, Y. (2015). An Insight of Sustainable Development Professional in Malaysia A Study Among Construction. 2(2), 56-64.

Zhuang, W.-L., Wu, M., \& Wen, S.-L. (2013). Relationship of mentoring functions to expatriate adjustments: comparing home country mentorship and host country mentorship. The International Journal of Human Resource Management, 24(1), 35-49. 